\title{
Puzzling (IRIDA-like and hemolytic) anemia in a child with idiopathic pulmonary hemosiderosis
}

Motokazu Nishikado $^{1}$, Hitoshi Awaguni ${ }^{1}$, Jun Shinozuka ${ }^{1}$, Kenichi Okumura ${ }^{1}$, and Shinsaku Imashuku ${ }^{2}$

${ }^{1}$ Uji Tokushukai Medical Center

${ }^{2}$ Takasago-Seibu Hospital

September 24, 2021

\section{Hosted file}

R5-manuscript.docx available at https://authorea.com/users/435671/articles/538533-puzzlingirida-like-and-hemolytic-anemia-in-a-child-with-idiopathic-pulmonary-hemosiderosis 